\title{
Acatisia associada à bromoprida em um paciente deprimido usando fluvoxamina
}

\author{
Akathisia associated with bromopride in a \\ depressed patient using fluvoxamine \\ Tábita Juliana Tomelin', Hélio Anderson Tonelli'
}

\section{RESUMO}

Contexto: A acatisia é definida clinicamente como uma sensação de agitação associada à necessidade de produção de movimentos, comumente deflagrada por bloqueadores dopaminérgicos, como os neurolépticos, podendo ocorrer também durante o tratamento com inibidores seletivos de recaptação de serotonina. É possível que drogas não psiquiátricas que bloqueiem receptores dopaminérgicos, como a bromoprida, possam causar sintomas extrapiramidais. Objetivos: Descrever um desfecho desfavorável caracterizado por acatisia em um paciente depressivo previamente estabilizado com fluvoxamina, após usar bromoprida. Métodos: Descrição de um caso. Resultados: Sr. J., paciente deprimido de 47 anos, estava estabilizado com fluvoxamina $200 \mathrm{mg}$ por dia. Iniciou abruptamente com quadro de inquietação e necessidade de produzir movimentos voluntariamente a fim de aliviar esse desconforto. Há quatro dias havia iniciado o uso de bromoprida $30 \mathrm{mg}$ por dia para tratamento de dispepsia. A suspensão da bromoprida promoveu alívio imediato dos sintomas. Conclusão: A bromoprida, um bloqueador dopaminérgico, pode ter deflagrado acatisia em um paciente em uso de fluvoxamina. Os mecanismos farmacológicos relacionados a esse desfecho são discutidos.

\section{ABSTRACT}

Background: Akathisia is clinically defined as a sensation of restlessness associated to a necessity to produce movements, commonly triggered by dopaminergic blockers, like neuroleptics, and it might occur during treatment with selective serotonine reuptake inhibitors. It is possible that non psychiatric drugs that block dopaminergic receptors, like bromopride, might cause patients to develop extrapyramidal symptoms. Objectives: To describe an unfavorable outcome clinically characterized by akathisia in a depressed patient previously stabilized with fluvoxamine, after using bromopride. Methods: Case report. Results: Mr J, 47 year-old depressed patient, had been stabilized with fluvoxamine $200 \mathrm{mg}$ a day. He began abruptly with restlessness and an urgency to produce voluntary movements in order to alleviate such discomfort. Four days earlier he began using bromopride $30 \mathrm{mg}$ a day to treat dyspepsia. Withdrawn of bromopride promoted an immediate relieve of the symptoms. Conclusion: Bromopride, a dopaminergic blocker, might have triggered akathisia in a patient using fluvoxamine. The pharmacologic mechanisms regarding this outcome are discussed.

1 Instituto de Psiquiatria do Paraná (IPP). 


\section{INTRODUÇÃO}

Está bem estabelecido que inibidores seletivos da recaptação de serotonina (ISRS), como a fluvoxamina, podem induzir sintomas extrapiramidais (SEPS) ao longo do tratamento. Leo', ao revisar 71 relatos de caso de SEPs induzidos por ISRS, reportou que a acatisia foi o SEP mais comumente associado ao uso dessa classe de antidepressivos, seguido de distonia, parkinsonismo e estados semelhantes à discinesia tardia. A acatisia, comumente descrita como um estado de intensa agitação psicomotora e necessidade de produção de movimentos ${ }^{2}$, é indesejável tanto pela grande repercussão negativa na qualidade de vida dos pacientes quanto pelo risco de suicídio associado e descrito em alguns estudos ${ }^{3}$.

SEPs são comuns em pacientes usando bloqueadores dopaminérgicos de alta potência como o haloperidol, e seu aparecimento em pacientes em uso de ISRS isoladamente pode ser explicado a partir de achados neurofisiológicos demonstrando efeitos inibitórios da serotonina sobre a transmissão dopaminérgica; assim, o aumento da disponibilidade de serotonina promovido pelos ISRS parece ter o efeito de diminuir a transmissão dopaminérgica central ${ }^{4}$. Quando um estado hipodopaminérgico acontece na via dopaminérgica nigroestriatal, aumentam-se as chances de ocorrência de SEPs².

Portanto, a coprescrição de ISRS com outros fármacos antidopaminérgicos, como os antipsicóticos de primeira geração, aumenta ainda mais o risco do aparecimento de SEPs; contudo, tais efeitos adversos podem ocorrer em pacientes utilizando exclusivamente ISRS. Isso se deve a determinados fatores predisponentes, como a presença de um transtorno do movimento, por exemplo, doença de Parkinson, história prévia de SEPs droga-induzidos (sensibilidade extrapiramidal) e possível deficiência de isoenzimas do citocromo P450, afetando o metabolismo de fármacos ${ }^{5}$.

A bromoprida é classificada como um procinético intestinal de ação antidopaminérgica, sendo utilizada clinicamente no tratamento de transtornos motores do trato gastrointestinal superior, incluindo dispepsia funcional, sintomas de estase gástrica de etiologia variada e vômitos ${ }^{6}$. Suas ações terapêuticas procinética e antiemética se devem, respectivamente, ao bloqueio dos efeitos inibitórios periféricos da dopamina sobre as fibras musculares do trato digestivo por meio do antagonismo de receptores dopaminérgicos do tipo D2 e ao bloqueio desses receptores em regiões centrais como a área postrema ${ }^{6}$. Como qualquer procinético antidopaminérgico, a bromoprida pode causar SEPs, embora esses efeitos sejam mais raros com esse agente do que com outros procinéticos, como a cleboprida, que se liga com maior afinidade ao receptor $\mathrm{D} 2^{7}$.

O relato a seguir descreve o caso de um paciente em uso prolongado de fluvoxamina para tratamento de um quadro depressivo, o qual não havia apresentado nenhuma queixa de SEP até ter recebido bromoprida, quando desenvolveu sintomas compatíveis com acatisia, resolvidos imediatamente após a suspensão do procinético.

\section{DESCRIÇÃO DO CASO}

J., 47 anos, branco, natural de Lages (SC), procurador, casado, curso superior completo.

Em 2005, procurou atendimento privado em consultório para tratamento de reagudização de quadro depressivo maior de intensidade grave, há cerca de um mês. O quadro caracterizava-se, em linhas gerais, por anedonia, desesperança, ruminações depressivas de menos-valia e culpa, insônia terminal e dificuldade para se concentrar. Tinha história de outros dois episódios depressivos semelhantes, o primeiro há mais de vinte anos e o segundo há cerca de oito anos, todos com remissão total após o uso de, respectivamente, clomipramina $150 \mathrm{mg}$ por dia e fluvoxamina $200 \mathrm{mg}$ por dia. Por conta do falecimento de seu psiquiatra, com quem se tratou nos últimos anos, permanecendo assintomático e funcional, procurou atendimento em outro serviço, onde foi orientado a começar a fazer uso de quetiapina $100 \mathrm{mg}$ e bromazepam $3 \mathrm{mg}$ por dia. Com essas drogas, refere ter se sentido muito mal, com uma sensação de piora dos sintomas depressivos e um forte desconforto físico, que descreveu como uma "espécie de inquietação". Em virtude desses efeitos, o paciente interrompeu o uso da quetiapina e manteve-se usando bromazepam até ter feito a avaliação aos meus cuidados. Os sintomas de inquietação remitiram imediatamente após a suspensão da quetiapina.

Diante do diagnóstico de transtorno depressivo recorrente, episódio atual moderado que ainda apresentava, e pela história de remissão sintomática com fluvoxamina, optou-se por reintroduzir esse antidepressivo, na dosagem de $200 \mathrm{mg}$ por dia, substituindo o benzodiazepínico por clonazepam $2 \mathrm{mg}$ à noite. Houve remissão gradual do quadro em um período de cerca de cinco semanas e o paciente permaneceu assintomático e trabalhando normalmente, quando por meio de um telefonema, a esposa informou que J. acordara "estranho" naquele dia, "chacoalhando muito na cama e com o olhar caído", indisposto para suas atividades laborativas às quais faltara naquele dia por estar se sentindo muito mal. Não havia perda da consciência, estando ele aparentemente lúcido. Ao exame, apresentava-se em bom estado geral, consciente, lúcido, orientado e colaborativo, queixando-se de intenso mal-estar que tinha dificuldade para descrever, mas caracterizado por impossibilidade de ficar parado e inquietação mental, bem como por necessidade de produzir movimentos pelo corpo, o que o induzia a "chacoalhar" na cama. Reforçava que o que sentia era muito diferente dos sintomas depressivos que já apresentara. Acrescenta que não conseguia ler nem assistir à televisão, pois nenhuma posição era confortável e a produção voluntária de movimentos ali- 
viava parcialmente seu desconforto. Não tinha sintomas psicóticos. Estava afebril e sem alterações dos exames clínico e neurológico. Questionado se havia alguma droga que J. teria começado a usar recentemente, ele prontamente respondeu que há cerca de quatro dias estava usando bromoprida $10 \mathrm{mg}$ de oito em oito horas para tratamento de uma dispepsia. Pensando em acatisia decorrente do bloqueio de receptores dopaminérgicos D2 centrais pela bromoprida e de possível interação farmacodinâmica desse fármaco com a fluvoxamina, piorando a intensidade da referida reação extrapiramidal, o paciente foi orientado a suspender a medicação procinéti$c a$, devendo suas queixas desaparecer em algumas horas. De fato, no dia seguinte à consulta, o paciente já estava melhor e dois dias após com remissão completa dos sintomas.

\section{DISCUSSÃO}

O presente caso ilustra uma situação clínica em que uma interação farmacodinâmica entre a fluvoxamina e a bromoprida desencadeou sintomas característicos de acatisia em um paciente aparentemente predisposto a SEPs. Tal predisposição pode ser inferida inicialmente a partir da história pregressa de intolerância à quetiapina, a qual teria provocado um estado de intenso "desconforto físico e inquietação", compatível com acatisia, motivando-o a suspender imediatamente esse agente. Embora a quetiapina seja um bloqueador D2 de baixa afinidade e com muito baixa probabilidade de desencadear SEPs, há relatos de caso descrevendo situações em que indivíduos propensos a SEPs desenvolveram acatisia e outros SEPs ao serem expostos a esse antipsicótico atípico ${ }^{8,9}$. Em relação à suscetibilidade individual ao desenvolvimento de SEPs, pode-se afirmar que ainda não existem fatores predisponentes claramente estabelecidos, todavia já foi sugerido que portadores de transtornos do humor (mais especificamente depressão) e pacientes com deficiência de ferro têm risco aumentado para acatisia quando expostos a drogas antidopaminérgicas ${ }^{10-12}$.

A relação temporal entre a introdução/suspensão da bromoprida e o início/remissão dos sintomas de acatisia no paciente em questão parece ser inequívoca e pode ser explicada como uma interação farmacodinâmica entre a fluvoxamina e a bromoprida: a primeira, ao aumentar os níveis centrais de serotonina - em consequência do papel regulador da serotonina sobre a liberação de dopamina -, propiciou diminuição dos níveis de dopamina nas vias dopaminérgicas centrais. Cabe ressaltar que tal diminuição não foi suficiente- mente intensa para desencadear SEPs enquanto o paciente utilizava apenas o antidepressivo, embora possa ter criado um estado de predisposição. Por sua vez, a bromoprida, ao bloquear receptores D2 centrais, provocou acentuação do estado hipodopaminérgico central, atuando como agente desencadeante da acatisia.

O presente caso clínico ilustra uma situação comum na prática diária, em que um paciente estabilizado em uso de um antidepressivo associa uma droga procinética vendida de forma relativamente liberal e, de certa forma, vista como "inocente", desenvolvendo um efeito colateral potencialmente grave.

Embora usuários de ISRS possam desenvolver acatisia quando em uso isolado dessas drogas ou em associações delas com outras (particularmente antipsicóticos típicos), é importante identificar outros fármacos que, como a bromoprida, são utilizados para o tratamento de condições não psiquiátricas e que tenham ações sobre o SNC, aumentando as chances de efeitos indesejáveis, na medida em que interagem com outros psicotrópicos.

\section{REFERÊNCIAS}

1. Leo RJ. Movement disorders associated with the serotonin selective reuptake inhibitors. J Clin Psychiatry. 1996;57(10):449-54.

2. Owens DGC. A guide to extrapyramidal side-effects of antipsychotic drugs. Cambridge: Cambridge University Press; 1999.

3. Besnier N, Gavaudan G, Navez A, Adida M, Courtet P, Lançon C. Clinical features of suicide occurring in schizophrenia. Risk-factors identification. Encephale. 2009;35(2):176-81.

4. Damsa C, Bumb A, Bianchi-Demicheli F, Vidailhet P, Sterck R, Andreoli A, et al. "Dopamine-dependent" side effects of selective serotonin reuptake inhibitors: a clinical review. J Clin Psychiatry. 2004;65(8):1064-8.

5. Lane RM. SSRI-induced extrapyramidal side-effects and akathisia: implications for treatment. J Psychopharmacol. 1998;12(2):192-214.

6. Tonini M, Cipollina L, Poluzzi E, Crema F, Corazza GR, De Ponti F. Clinical implications of enteric and central D2 receptor blockade by antidopaminergic gastrointestinal prokinetics. Aliment Pharmacol Ther. 2004;19:379-90.

7. Barreira RE, Magaldi RB. Distonia aguda relacionada ao uso de bromoprida em pacientes pediátricos. Rev Paul Pediatr. 2009;27(1):110-4.

8. Catalano G, Grace JW, Morales MJ, Cruse LM. Acute akathisia associated with quetiapine use. Psychosomatics. 2005;46(4):291-301.

9. Shah R, Grovers, Maheshwari U, Kate N, Malhotra N. Acute akathisia with quetiapine: a case report and review of literature. Indian J Pharmacol. 2010;42(6):416-7.

10. Koliscak L, Makela E. Selective serotonin reuptake inhibitor-induced Akathisia. J Am Pharm Assoc. 2003:49(2):28-36.

11. Barton A, Bowie J, Ebmeier K. Low plasma iron status and Akathisia. J Neurol Neurosurg Psychiatry. 1990;53(8):671-4.

12. Sachdev P. The epidemiology of drug-induced akathisia: Part I. Acute akathisia. Schizophr Bull. 1995:21(3):431-49. 